\title{
Characteristics of participants in an HIV prevention intervention for youth in Rwanda: results from a longitudinal study
}

\author{
Hanne Celis (1), Brian A. Jingwa (2), Olivier Degomme (1), \\ Ronan Van Rossem (1), Marleen Temmerman (1), \\ Kristien Michielsen (1)
}

(I) Ghent University, Belgium

(2) Hasselt University, Belgium

\begin{abstract}
Introduction. This paper studies determinants of participation in a peer-led school-based HIV prevention intervention in Rwanda. Methods. A baseline survey among I07I students (mean age I7 years) assessed potential determinants of participation, while a follow-up six months in the intervention measured actual participation in the intervention. Statistical models were built using multivariate linear and multinomial regression analysis predicting overall participation, participation in group discussions and individual counseling. Results. Those who recently had sex, had been tested for HIV, feel more susceptible to HIV, have a higher sexual self-concept, a more positive future perspective (only for non-sexually active), and boys, were more likely to participate in group activities. Also students from the same class as the peer educator and boarding school students were more likely to participate in group activities. Older students and those with low external health locus of control participated more in individual counseling. Discussion. Participation could be increased by investing in general well-being of young people, organizing girls-only activities, and diversifying activities.
\end{abstract}

Key words: selection bias, HIV prevention, participation rate, young people, Rwanda

\section{Introduction}

Background

Recent data show that the HIV epidemic worldwide is stabilizing: compared to $200 \mathrm{I}$ $20 \%$ less people were newly infected with HIV in 20II, while antiretroviral medication means that people with HIV survive longer. Nevertheless, with 2.2 million [2.2 million2.8 million] new infections in 20II, the HIV incidence remains at an unacceptably high level. Sub-Saharan Africa, in particular accounts for $69 \%$ of all people living with HIV/ AIDS, and remains severely affected (UNAIDS, 20I2b). Young people aged I 5 to 24 years are at high risk: about $40 \%$ of new HIV infections worldwide occur in this group and daily an estimated 500,000 young people are infected with a sexually transmitted infection other than HIV (UNFPA, 20II). Targeted prevention programs for this age group are 
essential to reversing the HIV epidemic (Coates, Richter, \& Caceres, 2008; Marston \& King, 2006). In Rwanda $3 \%$ of people aged I5-49, were living with HIV/AIDS in 20I0. HIV prevalence is highest among young women in urban areas (UNAIDS, 20I2a).

Since the beginning of the epidemic, prevention efforts have focused on reducing sexual risk behaviors of young people. These interventions often show significant changes in knowledge on HIV and sexual and reproductive health, but demonstrate less success in changing sexual behavior (Gallant \& Maticka-Tyndale, 2004; Harrison, Newell, Imrie, \& Hoddinott, 2010; Medley, Kennedy, O'Reilly, \& Sweat, 2009; Michielsen et al., 2010; Paul-Ebhohimhen, Poobalan, \& van Teijlingen, 2008). Studies that compare young people highly exposed to interventions with those who have had less exposure often report more positive changes in sexual behavior in the former group (Kim Young, 200I; Magnani, MacIntyre, Karim, Brown, \& Hutchinson, 2005; Maticka-Tyndale, Wildish, \& Gichuru, 2007; Plautz, Meekers, \& Neukom, 2003; Speizer, Tambashe, \& Tegang, 200I; Underwood, Hachonda, Serlemitsos, \& Bharath-Kumar, 2006). However, the profile of those active participants is never further elaborated upon. Self-selection to participate or not is mentioned as a limitation in a number of evaluation studies, although more in the field of biomedical HIV prevention or other health behaviors (e.g. self-selection in voluntary counseling and testing services, in prevention of mother to child transmission interventions, or in smoking cessation or diet promotion) than in behavioral interventions to reduce sexual risk behavior (McCree \& Jones, 2010; Nyblade et al., 200I). Determinants of participation in behavioral HIV prevention interventions for youth is an under-represented topic in HIV prevention research. Nevertheless, elaborating on the profile of participants is important as many of these programs are of a voluntary nature and people choose whether or not to participate, the results can be biased. The possible effects of a program might differ between voluntary participants and those who feel less tempted to participate on their own (Nyblade et al., 200I; Yang et al., 2007). If certain individual characteristics or determinants are to account for active participation, or if certain groups of young people are not likely to participate in interventions, interventions should be adapted in order to attract all young people in need of sexual and reproductive health information.

\section{Objectives and hypotheses}

This paper aims to identify determinants of participation and a profile of participants in a peer education HIV prevention program in secondary schools in the district of Bugesera (Rwanda).

The intervention was implemented by the Rwandan Red Cross Society and took place from August 2009 to October 20I0. Its goals were to increase knowledge of HIV, to reduce stigma and discrimination, to reduce sexual risk behavior and to promote voluntary HIV testing, by using peer education techniques.

There is a dearth of literature on the profile of participants in HIV prevention interventions. In most research self-selection in HIV prevention interventions is mainly indicated as a study limitation but studied no further. Therefore, our hypotheses were mainly based on field experience and self-selection literature in other health interventions 
(Berten \& Van Rossem, 2009; Hasson, Brown, \& Hasson, 20I0; Näslund, Fredrikson, \& Holm, I993; Oakley, Strange, Stephenson, Forrest, \& Monteiro, 2004; Painter et al., 2005; Robroek, van Lenthe, van Empelen, \& Burdorf, 2009; Speizer, Magnani, \& Colvin, 2003; UNFPA \& FHI, 2005; Vanderstraten, King, Grinstead, Serufilira, \& Allen, I995).

The first hypothesis is that the decision to participate in the intervention is influenced by the students' pre-intervention sexual behavior and knowledge: those with risky sexual behavior were expected to participate more, as it is the objective of the intervention to provide information on how to deal with sexual risks. Previous research has shown that interventions tend to reach those young people who already have high levels of knowledge about HIV (Berten \& Van Rossem, 2009; Oakley et al., 2004; Speizer et al., 2003). We hypothesize that students who have had an HIV test are also expected to participate more, since they have been directly confronted with their risk of infection and their vulnerability.

Secondly, young people who before the start of the intervention have the intention to use a condom or abstain from sex are expected to participate more, because they might seek assistance to realize these intentions (Hall, Bergman, \& Nivens, 20I4; Hasson et al., 20I0).

Thirdly, we hypothesize that participation is also influenced by personal-psychological characteristics. A) We expect that those students with a positive perspective for the future will participate, as unsafe sexual behavior and ill-health may compromise the positive future perspective (Magnani et al., 2005; Näslund et al., I993). B) Students with a high internal locus of control believe they have control over their own health, while those with a high external locus of control consider their health determined by external factors (Rotter, I954). We expect the participation of those with a high external locus of control to be higher, as they may be more likely to search for external help in managing their health. C) We also expect students with a positive sexual self-image to participate more. Since they are more at ease with their own sexuality, they might not be afraid to participate in public activities on sexual health topics (Näslund et al., I993). D) Furthermore those students with a high perceived susceptibility to HIV would be more likely to participate. They feel vulnerable to HIV infection and are thus more likely to seek help to deal with this vulnerability (Ma et al., 20I2; Yang et al., 2007).

Finally, we hypothesize that participation in the intervention is determined by practical arrangements (Ma et al., 20I2). Students who were in the same class as a peer educator are expected to have easier access to information on the intervention and hence are expected to participate more. Students who live in boarding schools on the school grounds have more opportunities to participate in the activities than day students.

Furthermore, we hypothesize that not all intervention activities appeal equally to all students and that the strength of the hypothesized determinants of participation depends on the type of activity. For example, individual counseling is a participant initiated activity while a drama play is initiated by the peer educator and participation is more anonymous. It is expected that participation in both activities is influenced to a different extend by the above mentioned determinants. 


\section{Methods}

The intervention

The intervention was a peer-led HIV prevention intervention. In each of the eight schools five students were selected by the disciplinary teacher, who lives in the school and knows the students well, based on a number of predefined criteria (sex, study year and personal characteristics including having an open attitude, integrity, confidentiality, and entrepreneurship). These peer educators received an initial six days of training, two days of follow-up training after a year and regular intermediary meetings. In each school, a trained teacher provided support for the peer educators. Peer educators were expected to provide their fellow students with consistent and correct information about HIV/AIDS, sexually transmitted infections (STIs), pregnancies and other sexual health issues. This was done through activities such as drama plays, songs and group discussions and by giving individual counseling to the students upon request. At the start of the project, the peer educators were introduced in all classes and activities were announced during morning gatherings. The activities aimed atreaching the large majority of the students, both boys and girls. Each student was free to decide whether or not to attend.

The intervention showed limited effects. Time trends in sexual risk behavior (being sexually active, sex in last six months, condom use in last sexual encounter) were not significantly different in students from intervention and control schools, but the intervention did significantly reduce reported stigma (Michielsen, 2012). However, studying the profile of the participants remains important. To gain a more complete insight into the effectiveness of programs it is important that all targeted youth can participate and that differences between participants and non-participants are elaborated upon.

\section{Study design}

The study was part of a larger study on the impact of the peer education HIV prevention project in secondary schools in Rwanda, using a non-randomized controlled/community trial (Michielsen et al., 20I2). In fourteen secondary schools - eight intervention and six control schools - students from the second and fifth year were followed over eighteen months. Standardized questionnaires were carried out at three different points in time. In March 2009 the baseline study took place, followed by measurements taken during the intervention in March 2010 (TI) and in September 2010 (T2).

This paper deals with self-selection in the HIV prevention intervention and therefore only includes data from the eight schools where the intervention was implemented. We studied the (non-)participation of the students during the first part of the intervention (from July 2009 to March 2010), thus including data from baseline and Tr.

\section{Sample}

Eight schools in the intervention area were selected to participate on a purposive basis. The selection criteria are location (urban/rural), education offered (lower and/or higher secondary education), organizing authority (public, semi-public, private), school size (large, medium, small) and religious affiliation (Catholic, Muslim, no religious af- 
filiation) (see Table I). No schools refused to participate. The second and fifth year were selected because these students had the highest probability of still being in school the next school year, drop-out rates being the highest after the third year (the end of lower secondary education), and after the sixth year (the end of secondary education).

\begin{tabular}{l|l|l|l|l|l} 
School & Location & $\begin{array}{l}\text { Lower or } \\
\text { higher } \\
\text { secondary } \\
\text { education }\end{array}$ & $\begin{array}{l}\text { Number of } \\
\text { students } \\
(\mathbf{2 0 0 9})\end{array}$ & $\begin{array}{l}\text { Public or } \\
\text { private }\end{array}$ & $\begin{array}{l}\text { Religious } \\
\text { background }\end{array}$ \\
\hline School I & Urban & higher & 50 I-750 & Public & No \\
\hline School 2 & Urban & $\begin{array}{l}\text { lower and } \\
\text { higher }\end{array}$ & $>750$ & Private & No \\
\hline School 3 & Urban & lower & $50 I-750$ & Public & No \\
\hline School 4 & Rural & $\begin{array}{l}\text { lower and } \\
\text { higher }\end{array}$ & $>750$ & Private & Catholic \\
\hline School 5 & Rural & lower & $25 \mathrm{I}-500$ & Public & No \\
\hline School 6 & Rural & $\begin{array}{l}\text { lower and } \\
\text { higher }\end{array}$ & $<250$ & Private & Islamic \\
\hline School 7 & Rural & lower & $25 \mathrm{I}-500$ & Public & No \\
\hline School 8 & Rural & $\begin{array}{l}\text { lower and } \\
\text { higher }\end{array}$ & $>750$ & Public & No
\end{tabular}

Table 1. Characteristics of the participating schools

\section{Data collection}

The questionnaire was developed in French, translated in Kinyarwanda and back translated in French and was pre-tested for comprehensibility and language on thirty students of the first year of secondary education. The questionnaires were self-administered in classrooms or refectories. Only research staff were present during survey administration. A coding system guaranteeing confidentiality was used to match students over the waves. For the follow-up surveys schools were visited up to three times to find the same students. Data-entry was done using Optical Mark Recognition software.

\section{Ethics}

The study was approved by the Ethics Commission of Ghent University Hospital (2008/485), the Rwanda National Ethical Committee (42/RNEC/2009), the Rwandan Institute for Statistics (130/2009/INSR) and the Rwandan National AIDS Control Committee (or35/CNLS/2009/S.E). School principals gave permission to do the study in their school. Before the start of the survey, the concepts of voluntary participation and confidentiality were explained to the students and they were asked to complete and sign an informed consent form. 


\section{Measures}

\section{Dependent variables}

The dependent measure in this study is the participation in the peer education program. Students were asked if they participated in six different activities or services of the intervention (Table 2). Respondents had to indicate if they participated passively, actively or did not participate (scored as $0, \mathrm{I}, 2$ ). Passive participation was defined as observing the activity. Active participation was defined as having an active input in the activity, e.g. asking a question, participating in a discussion or playing a role in a theatre play. A general participation scale with a range from o to 12 was constructed from these items using sum scores (Cronbach's alpha: 0.834). A difference of I point on the participation scale indicates that a student either participated in more different activities, or participated more actively in an activity. The scale was developed for all students who responded to at least one question.

To determine whether students with different profiles participated in different types of activities, we selected two distinct activities from these six: individual counseling by a peer educator (a participant initiated activity in which one participant or a small group of participants asked questions or discussed a problem with the peer educator) and group activity (a peer educator initiated activity, e.g. drama play, in which the peer educator presents a self-chosen topic to a large group of students).

\section{Independent variables}

First, we studied pre-intervention behavior and knowledge, using an adapted version of a questionnaire of the World Health Organization (Cleland, 200I). Sexual activity was measured through two questions: "did you ever have sex? (yes/no)" and "did you have sex in the last 6 months? (yes/no)". Condom use was measured by one variable asking if the respondents had used a condom during the last sexual intercourse. Knowledge was measured through two questions: we presented students with eleven possible protective measures and nine possible transmission modes and asked them to indicate if the items were true or false. Students were asked if they had been tested for HIV (no/yes/ don't remember).

Four personal-psychological scales are included in the analysis. First, a health locus of control scale of II items developed by Wallston et al (Wallston, 2005) measured the extent to which people feel they have control over their health (sum scores, range II-44, Cronbach's alpha=0.59). We divided the scale into two sub-scales: internal locus of control (feeling one has control over his or her own health) and external locus of control (feeling that other people or external factors control one's health). A second personal scale that was included is the participants vision of the future developed by Ducot \& Spira (Ducot \& Spira, I993). The scale measured the extent to which respondents have an optimistic or a pessimistic future vision (sum scores, range o to 9; Cronbach's alpha 0.64 ). Thirdly, we included a scale measuring the sexual self-concept of the respondents. This scale measured whether a respondent considers him/herself physically and emotionally ready to have sexual intercourse (sum scores, Cronbach's alpha 
o.60) (Winter, I988). Finally, perceived susceptibility to HIV infection is measured using a 4-item scale developed by Lux \& Petosa (Lux \& Petosa, I994) (sum scores, range o-I6, Cronbach's alpha o.67).

The intention to use a condom and the intention to abstain were measured using one question: 'Do you intend to use a condom at next sexual intercourse?' and 'Do you intend to abstain from sex during the next 6 months?'.

Practical barriers and facilitators for participation in the intervention are living situation and proximity to peer educators. Students were asked to indicate where they lived during the school year: in a boarding school on the school grounds, in a private boarding school, or with their parents/family. The proximity to peer educators was measured by asking the students if they were in the same class as a trained peer educator.

\section{Data analysis}

Data analysis was done in Stata version II (Stata Corporation, College Station, TX) and SAS version 9.2 (SAS Institute Inc., Cary, North Carolina). Adjusting for intra-cluster correlation was considered for the sample size calculation, but was omitted in post hoc power calculations because of weak, non-significant correlations between students in each of the school.

Two types of models were built. First, for the categorical dependent variables (participation in individual counseling and group activities) we used multinomial logistic regression with backward variable selection. Second, to identify predictors of the general participation scale we used linear regression models, also with backward variable selection. Competing models were fitted based on the assumed distribution of the variable as well as how its mean is related to the independent predictors (McCullagh \& Nelder, I989). Akaike Information Criterion (AIC) was used to select the best model (Akaike, I973, I974). For the general participation scale the best fit model used a gamma distribution and a log link.

\section{Results}

Participation in the Peer Education HIV prevention intervention

At baseline ro7r students participated in the survey. At TI, 805 students participated, resulting in a drop-out of $24.8 \%$. At TI reasons for not completing the study were drop-out of school (71\%), illness or absence from school at the time of survey (29\%). We visited the schools up to three times to retrieve students. As the study took place over a period of two school years, a substantial group of students had left the school by the time of Tr. The analysis included respondents that completed both surveys at baseline and Tr.Participation in the peer education program was relatively low: on the general participation scale ranging from o to $\mathrm{I} 2$, the median score was 3 (mean: $3 \cdot 47$, s.d. 0.I2, $\mathrm{n}=789$ ). Table 2 shows participation of students in the different activities. 


\begin{tabular}{|c|c|c|c|}
\hline Participated in...? & No & $\begin{array}{c}\text { Passively } \\
\text { participated }\end{array}$ & $\begin{array}{c}\text { Actively } \\
\text { participated }\end{array}$ \\
\hline $\begin{array}{l}\text { Group discussions (e.g. drama plays) } \\
\qquad \begin{array}{c}(\mathrm{n}=7 \mathrm{I} 7) \\
\%(\mathrm{n})\end{array}\end{array}$ & $47 \cdot 7(342$ & $32.4(232)$ & I9.9 (I43) \\
\hline $\begin{array}{l}\text { Individual (or small group) counseling } \\
\qquad \begin{array}{c}(\mathrm{n}=667) \\
\%(\mathrm{n})\end{array}\end{array}$ & 68.8 (459) & I5.89 (I06) & I5.3 (I02) \\
\hline $\begin{array}{l}\text { Morning sessions/school breaks } \\
\qquad(\mathrm{n}=678) \\
\%(\mathrm{n})\end{array}$ & $55 \cdot 3(375)$ & $25 \cdot 5(\mathrm{I} 73)$ & I9.2 (I30) \\
\hline $\begin{array}{c}\text { Class activities }(\mathrm{n}=670) \\
\qquad \%(\mathrm{n})\end{array}$ & $60.3(404)$ & $2 \mathrm{I} \cdot 3$ (I43) & I8.4 (I23) \\
\hline $\begin{array}{l}\text { Sponsored event }(\mathrm{n}=655) \\
\qquad \%(\mathrm{n})\end{array}$ & $47.63(312)$ & $25.2\left(\mathrm{I}_{6} 5\right)$ & 27.I8 (I78) \\
\hline $\begin{array}{l}\text { Other }(\mathrm{n}=63 \mathrm{I}) \\
\%(\mathrm{n})\end{array}$ & $43.9(227)$ & 26.8 (I69) & $29 \cdot 3(185)$ \\
\hline Total & $43 \cdot 4$ & \multicolumn{2}{|c|}{56.6} \\
\hline
\end{tabular}

Table 2. Participation in different aspects of the peer education intervention

\section{Difference between non-participants and participants}

The final models predicting the total participation scale, participation in group discussions and participation in individual counseling are shown in table 3 .

Our hypotheses were partially supported by the results. The first hypothesis, that pre-intervention behavior and knowledge determine participation, was supported for the group activities: those who recently had sex (in the six months before the study), were more likely to participate. Those students who had been tested for HIV were also more likely to participate in general and in group discussions. Knowledge about HIV had contradictory results: while those with higher knowledge levels showed higher levels of participation in general, those with lower levels participated more in group activities. Condom use at last sex was dropped in the final model and cannot be considered a predictor of participation.

The second hypothesis, that those who intend to use a condom or to abstain from sex are more likely to participate, was rejected. For none of the outcomes were these variables retained in the final model, hence baseline intentions do not seem to influence participation.

Thirdly, we hypothesized that those students who feel more susceptible to HIV, have a higher sexual self-concept, a more positive future vision or a higher health locus of control would participate more. While these personal-psychological characteristics did not seem to have an impact on participation in individual counselling, the hypothesis was partially supported for general participation and group activities. 
Those with higher perceived susceptibility and those with a more positive sexual self-concept were indeed more likely to participate. Since the statistical model controlled for interaction effects, even for those students who do not display sexual risk behavior, perceived susceptibility was a determinant of participation.

For health locus of control our hypothesis is rejected: those students with a low locus of control (or a high external locus of control) were actually more likely to participate, both generally and in individual counselling.

Future perspective did have an impact on general participation and participation in group activities, but this impact depended on sexual activity. Students who never had sex were more likely to participate when they had a more positive future perspective. The survey also asked for reasons why young people had not yet had sex (because you do not feel ready, did not yet have the opportunity, think sex before marriage is a sin, are afraid to get pregnant or are afraid for HIV/STI infection). Those young people who had not yet had sex because they are afraid to get HIV/STI also scored significantly higher on the future perspective scale $(n=462, t=-2.42, p<0.05)$. It is possible that their choice not to have sex is a conscious choice, hence their participation in the group activities.

The final hypothesis was supported: participation in the intervention depends on practical circumstances. Being in the same class as a peer educator was a significant predictor of all outcomes. Also the living situation was important for general participation and participation in group activities. Students who resided in a boarding school on school ground participated more, compared to a boarding school outside the school and even more as compared to students living with their family. Living situation was not important for participation in individual counseling.

Next to these hypotheses we found that boys were more likely than girls to participate in group discussions and scored higher on the general participation scale, even though this difference was small.

The results showed large differences between making use of individual counseling services of the peer educators and group participation or general participation. This activity appealed more to older students, while age was not a significant predictor of group or general participation. Although living situation was an important predictor for general participation and group participation, it was not important for participation in individual counseling. Also sexually active students seemed to use this service less readily, in contrast to group activities, where sexually active students participated more easily. All predictors were more important for active participation than for passive participation. 


\begin{tabular}{|c|c|c|c|c|c|}
\hline & 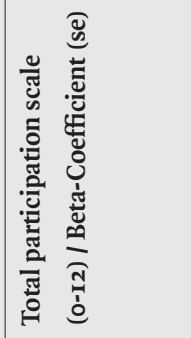 & 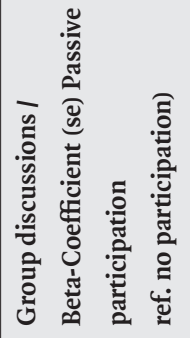 & 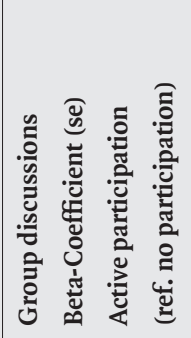 & 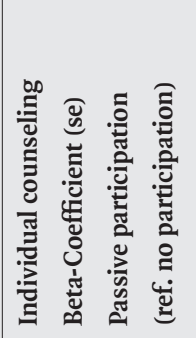 & 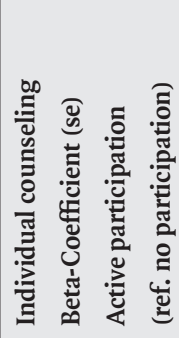 \\
\hline $\begin{array}{l}\text { Sex } \\
\text { Boys }\end{array}$ & $0.20(\mathrm{o} . \mathrm{II})^{\star}$ & $0.66(0.32)^{\star \star}$ & $0.72(0.38)^{\star \star}$ & & \\
\hline Age & & & & $0.15(0.08)^{\star}$ & $0.14(0.08)^{\star}$ \\
\hline $\begin{array}{l}\text { in the same class as a } \\
\text { peer educator } \\
\text { Yes }\end{array}$ & $0.7 \mathrm{I}(0.10)^{\star \star \star}$ & I.6I $(0.30)^{\star \star \star}$ & $2.47(0.37)^{\star \star \star}$ & $0.63(0.32)^{\star \star}$ & I. $80(0.34)^{\star \star \star}$ \\
\hline $\begin{array}{l}\text { living situation } \\
\text { private boarding } \\
\text { school outside school } \\
\text { parents/family } \\
\text { (ref: boarding school on } \\
\text { school grounds) }\end{array}$ & $-0.26(0.13)^{\star \star}$ & $\begin{array}{l}-0.75 \\
(0.36)^{\star \star \star \star}\end{array}$ & $-I .39(0.47)^{\star \star \star}$ & & \\
\hline $\begin{array}{l}\text { ever had sex } \\
\text { Yes }\end{array}$ & $0.17(0.37)$ & $0.60(1.02)$ & $\mathrm{I} .29(\mathrm{I} .35)^{\star \star}$ & $-0.34(0.39)$ & $-0.78(0.45)^{\star}$ \\
\hline $\begin{array}{l}\text { had sex in last } 6 \text { months } \\
\text { Yes }\end{array}$ & $0.40(0.22)^{\star}$ & $0.14(0.60)$ & $\mathrm{I} .88(0.82)^{\star \star}$ & & \\
\hline $\begin{array}{l}\text { knowledge HIV protec- } \\
\text { tion scale }\end{array}$ & $0.07(0.04)^{\star}$ & $-0.24(0.14)^{\star}$ & $-0.4 \mathrm{I}(0.17)^{\star \star}$ & & \\
\hline $\begin{array}{l}\text { external locus of control } \\
\text { scale }\end{array}$ & $0.04(0.02)^{\star}$ & & & $-0.02(0.07)$ & $0.2 \mathrm{I}(0.07)^{\star \star \star}$ \\
\hline future perspective scale & $0.06(0.03)^{\star \star}$ & $0.04(0.09)$ & $0.27(0.11)^{\star \star}$ & $0.13(0.09)$ & $0.13(0.09)$ \\
\hline $\begin{array}{l}\text { perceived susceptibility } \\
\text { scale }\end{array}$ & $0.03(0.02)^{\star}$ & $0.004(0.05)$ & $0.14(0.06)^{\star \star}$ & & \\
\hline sexual self-concept scale & & $0.12(0.07)^{\star}$ & $0.18(0.08)^{\star \star}$ & & \\
\hline $\begin{array}{l}\text { ever had HIV test } \\
\text { yes }\end{array}$ & $0.36(0.1 \mathrm{Ir})^{\star \star \star}$ & $0.66(0.29)^{\star \star}$ & $0.98(0.37)^{\star \star \star}$ & & \\
\hline $\begin{array}{l}\text { ever had sex }{ }^{\star} \text { future } \\
\text { perspective }\end{array}$ & $-0.10(0.1 \mathrm{II})^{\star}$ & -0.19 (0.18) & $-0.53(0.25)^{\star \star}$ & & \\
\hline intercept/constant & $-2.2(\mathrm{I} .23)^{\star}$ & $0.2 \mathrm{I}(\mathrm{I} .43)$ & $-\mathrm{I} .76(0.25)$ & $-4.97(\mathrm{I} .57)^{\star \star \star}$ & $-7.10(1.64)^{\star \star \star}$ \\
\hline
\end{tabular}




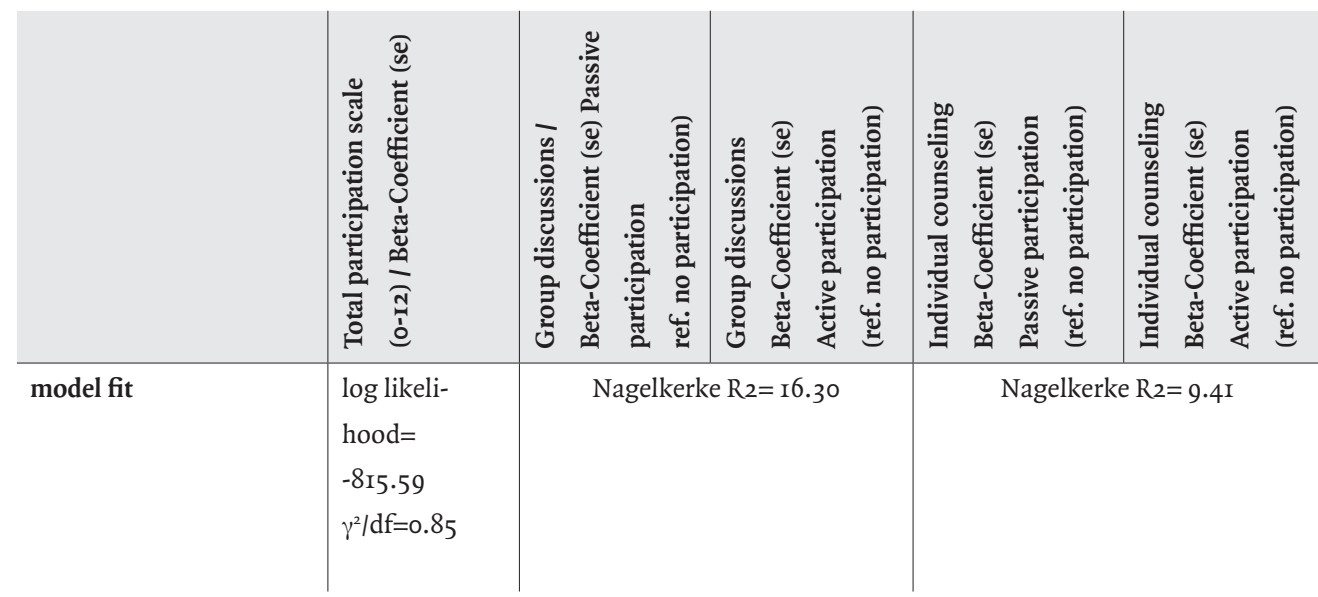

Table 3. Coefficients of predictors of participation in the intervention

* significant at level $p<0.10$ / ** significant at level $p<0.05 /{ }^{* * *}$ significant at level $p<0.01$

Independent variables included in the full model: sex, age, being in the same class as a peer educator, living situation, perceived susceptibility, perceived severity, knowledge of HIV protection methods, ever had sex, had sex in the last 6 months, intention to abstain in the next 6 months, intention to use condom at next sexual intercourse, internal locus of control, external locus of control, future perspective, sexual self-concept, ever had HIV test.

\section{Discussion and conclusion}

Profile of participants in group and individual activities

General participation in the intervention and participation in group activities had multiple overlapping predictors. The fact that the group discussions were the most visual part of the intervention could explain the overlap between the general participation scale and the variable measuring participation in the group activities. We did see large differences in type of participants comparing group discussions with individual counseling. We could say that group activities are attended by three categories of students. First, we see that students with a positive sexual self-concept, that is those who consider themselves ready to take decisions concerning sexual intercourse and have positive attitudes towards sexuality, are more likely to participate (actively) in group activities and score higher on the general participation scale Students who are more positively aware of their sexuality may feel more at ease communicating in public on this sensitive topic (Flisher, Parry, Bradshaw \& Juritz, I997; Harrison et al., 2010; Magnani et al., 2005; Winter, I988).

In general in Rwandan culture, it can be considered a sign of masculinity to have sex, while for girls openly talking about sex is a taboo (Musabyimana, 2006; Olawaiye, 20I0; Vanderstraten et al., I995). This could also explain why group activities are better attended by boys. Although the difference was small, there was an indication that boys participated more than girls. This is confirmed by qualitative research in the same population that found that girls participated less in activities in which their active input was needed, such as discussions in smaller groups. Several students and teachers also stated 
that girls stayed more in the background when sexual matters were discussed, out of fear of being portrayed as sexually promiscuous (Celis, 2010).

Secondly, practical considerations play a large role in participation in group activities (Celis, 2010; Maticka-Tyndale \& Barnett, 2010; Paul-Ebhohimhen et al., 2008). Life in boarding schools in Rwanda has a particular character; students only return home two or three times a school year and spend most of their evenings and weekends in the school. If peer educators organize an activity during this free time, only boarding school students have the opportunity to participate and see what is going on. Classmates are also more likely to be informed on the activities that are organized, since they have more opportunities to interact with the peer educator.

Thirdly, we identify a group of students that participates consciously in the group activities. These are students who have been confronted with HIV but are not necessarily at risk: those who were recently sexually active (in the last six months), those who feel susceptible to HIV infection and those who have been tested for HIV. Also students with a positive future perspective who abstain from sexual intercourse out of fear of HIV infection participated more in group activities. They could be 'conscious virgins' because they consider the risk for HIV infection too high to compromise their future perspective (Harrison et al., 2010; Magnani et al., 2005; Speizer et al., 2003). Students with a high external locus of control feel their health depends on external factors and persons. A possible explanation for their higher participation could be that they think peer educators (i.e. external factors) can influence their health.

For individual counseling the results did not allow us to distill one or more profiles of participants. However, we did see that older youths prefer to participate in individual counseling. It may be that older youth do not feel at ease discussing sexuality issues in a group of younger students, but prefer to select a peer educator they trust and enter into a face-to-face or small-group counseling activity.

\section{Recommendations for future interventions}

Even in the relatively homogeneous population of school-going youth, participation differs strongly depending on the type of activity. Therefore, the activities chosen to organise in an intervention have consequences as to who will participate.

Although the difference was not very large, there was an indication that boys participated more than girls. This is confirmed by qualitative research in the same population that found that girls participated less in activities in which their active input was needed, such as discussions in smaller groups. Several students and teachers also stated that girls stayed more in the background when sexual matters were discussed, out of fear to be portrayed as sexually promiscuous (Celis, 2010). This gender disparity in participation might be answered to by creating girls-only spaces or activities (Bruce, 2007). A more fundamental solution is that interventions should aim to influence norms so that girls feel free to publicly express their thoughts and ideas on sexuality and to publicly show their interest in these topics (Celis, 2010; Musabyimana, 2006; Olawaiye, 2010; Vanderstraten et al., 1995). 
Since a positive future perspective and a positive sexual self-concept contribute to increased participation, it seems important to broaden the scope of HIV prevention interventions and invest in the general well-being of young people (Harrison et al., 2010; Speizer et al., 2003). This observation is twofold. First, concerning the content of interventions, young people should be taught to feel more confident about themselves and their sexual feelings. This could be achieved by enlarging HIV prevention to more general comprehensive sexuality and relationship education (WHO Regional Office for Europe and BZgA, 20IO). Second, it means that HIV prevention efforts should be embedded in more structural interventions (e.g. education, scholarship programs) giving young people more perspective in life (Underwood, Skinner, Osman, \& Schwandt, 20II).

When using group activities as a method of prevention, program managers need to be aware that mostly the more outgoing and self-confident young people will participate, and that alternatives need to be put into place to reach the more timid students. Since these group activities appeal to those young people who have the opportunity to participate and who are looking for an activity in their free time, it is essential that they are organized for moments where all students can participate. Additional attention in peer education training should go to how to approach and reach the target population more effectively (Maticka-Tyndale \& Barnett, 20I0).

It seems important to diversify activities in interventions, since they appeal to different audiences. Individual counselling was actively used by $15 \%$ of respondents, but this participation could only be predicted by pre-intervention characteristics such as external locus of control and age. It was also highly influenced by the presence of a peer educator in the class. It is possible that participation depends on ad hoc questions or needs, and is therefore not regular or systematic. It is, however, positive to have such a service in place for confidentiality and sensitive questions, and to cater for less outgoing students; and it should be promoted more for respondents who do not have a direct bond with a peer educator.

The results also show that there is a group of students that is not participating: they might not be aware that they are at risk of HIV infection, they might not be aware of the intervention activities, the intervention activities do not appeal to them, or they might just not be interested in the topic. In order to reach this group, a compulsory activity would be welcomed, explaining the intervention and the basic concepts of sexual and reproductive health and healthy behavior. A school is a good setting to organize this.

\section{Limitations}

We analyzed the data on the assumption that everyone who wanted to participate in the peer education activities could participate. The only variables to confirm this assumption was the living situation of the students. We did indeed see that students who live in boarding schools on campus participate more than those in private boarding schools off campus and those living with their parents or family. There may be other obstructions, e.g. peer pressure not to participate, that were not taken into account. Second, the scales used in this study had relatively low Cronbach's Alpha scores. The scales were adapted 
versions of validated scales, though the fact that they were not validated for the specific population of school-going youth in Rwanda, may be an explanation for the relatively low scores. Third, our selection of covariates was made based on existing scientific literature and field experience. It is possible that other factors exist that may influence participation in the intervention. Finally, while regression analysis is appropriate to study the objective, it did not allow for more exploratory analyses. Therefore, it is possible that other, possibly non-linear, relationships exist between the variables. Despite these limitations we are confident of the reliability of our results, given that predicting factors were consistently stronger for active than for passive participation and that we could distinguish specific categories of participants.

\section{Acknowledgements}

This study was financially supported by the Research Foundation Flanders (FWO). We also thank the Rwandan Red Cross Society and the Belgian Red Cross Flanders for logistic support.

\section{References}

Akaike, H. (1973). Maximum Likelihood Identification of Gaussian Autoregressive Moving Average Models. Biometrika, 6o(2), pp. $255-265$.

Akaike, H. (1974). New Look at Statistical-Model Identification. Ieee Transactions on Automatic Control, Acrg(6), pp. 7I6723.

Berten, H., \& Van Rossem, R. (2009). Doing worse but knowing better: An exploration of the relationship between HIV|AIDS knowledge and sexual behavior among adolescents in Flemish secondary schools. Journal of adolescence, 32(5), pp. I303-1319. doi: DOI ro.ror6/j.adolescence.2008.12.004.

Bruce, J. (2007). Girls left behind: Redirecting HIV interventions toward the most vulnerable. In: PopulationCouncil (Ed.), Promoting healthy, safe and productive transitions to adulthood. New York: Population Council.

Celis, H. (2010). Evaluation of a Peer Education based HIV|AIDS Prevention Project with Rwandan Youth. (Master in Sociology), Ghent University, Ghent.

Cleland, J. (200I). Asking Young People about Sexual and Reproductive Behaviours. Illustrative Core Instruments. In: World Health Organization (Ed.). Geneva.

Coates, T.J., Richter, L., \& Caceres, C. (2008). Behavioural strategies to reduce HIV transmission: how to make them work better. Lancet, 372(9637), pp. 36-5I.

Ducot, B., \& Spira, A. (1993). Preventive Behavior of AIDS - Prevalence and Conductive Factors. Population, 48(5), pp. I479I504.

Flisher, A.J., Parry, C.D.H., Bradshaw, D., \& Juritz, J.M. (1997). Seasonal variation of suicide in South Africa. Psychiatry Research, 66(I), pp. I3-22.

Gallant, M., \& Maticka-Tyndale, E. (2004). School-based HIV prevention programmes for African youth. Social science \& medicine, 58(7), pp. I337-I35I.

Hall, M.E., Bergman, R.J., \& Nivens, S. (20I4). Worksite Health Promotion Program Participation. A Study to Examine the Determinants of Participation. Health Promot Pract, I5(5), pp. 768-776.

Harrison, A., Newell, M.L., Imrie, J., \& Hoddinott, G. (2010). HIV prevention for South African youth: which interventions work? A systematic review of current evidence. BMC public health, Io. doi: Io.II86/I47I-2458-I0-IO2.

Hasson, H., Brown, C., \& Hasson, D. (2010). Factors associated with high use of a workplace web-based stress management program in a randomized controlled intervention study. Health education research, 25(4), pp. 596-607.

Kim Young, M. (200I). Promoting Sexual Responsibility Among Young People in Zimbabwe. International family planning perspectives, 27(I), pp. II-I9.

Lux, K.M., \& Petosa, R. (I994). Using the Health Belief Model to Predict Safer Sex Intentions of Incarcerated Youth. Health Education Quarterly, 2I(4), pp. 487-497.

Ma, W., Raymond, H.F., Wilson, E.C., McFarland, W., Lu, H., Ding, X., Xiao, Y. (2012). Participation of HIV prevention programs among men who have sex with men in two cities of China: a mixed method study. BMC Public Health, I2, p. 847. doi: Io.II86/I47I-2458-I2-847. 
Magnani, R., MacIntyre, K., Karim, A.M., Brown, L., \& Hutchinson, P. (2005). The impact of life skills education on adolescent sexual risk behaviors in KwaZulu-Natal, South Africa. J Adolesc Health, 36(4), pp. 289-304.

Marston, C., \& King, E. (2006). Factors that shape young people's behaviour: a systematic review. The Lancet, 368 (9547), pp. I58I-I586.

Maticka-Tyndale, E., \& Barnett, J.P. (2010). Peer-led interventions to reduce HIV risk of youth: A review. Evaluation and program planning, 33(2), 98-II2. doi: DOI ro.ror6/j.evalprogplan.2009.07.00I.

Maticka-Tyndale, E., Wildish, J., \& Gichuru, M. (2007). Quasi-experimental evaluation of a national primary school HIV intervention in Kenya. Evaluation and program planning, 30(2), pp. I72-186. doi: Sor49-7I89(07)oooo8-o [pii] Io.ror6/j. evalprogplan.2007.0I.006.

McCree, D.M., \& Jones, K.T. (2010). African Americans and HIV/AIDS: Understanding and Addressing the Epidemic: Springer.

McCullagh, P., \& Nelder, J. (I989). Generalized Linear Models. New York: Chapman \& Hall.

Medley, A., Kennedy, C., O'Reilly, K., \& Sweat, M. (2009). Effectiveness of peer education interventions for HIV prevention in developing countries: a systematic review and meta-analysis. AIDS Education \& Prevention, 2I(3), pp. I8I-206.

Michielsen, K., Beauclair, R., Delva, W., Roelens, K., Van Rossem, R., \& Temmerman, M. (2012). Effectiveness of a peerled HIV prevention intervention in secondary schools in Rwanda: results from a non-randomized controlled trial. BMC public health, I2(I), p. 729. doi: I0.II86/I47I-2458-I2-729.

Michielsen, K., Chersich, M., Luchters, S., De Koker, P., Van Rossem, R., \& Temmerman, M. (2010). Effectiveness of HIV prevention for youth in sub-Saharan Africa: systematic review and meta-analysis of randomized and nonrandomized trials. AIDS, 24(8), pp. II93-I202.

Musabyimana, G. (2006). Pratiques et rites sexuels au Rwanda. Paris: L'Harmattan.

Näslund, G.K., Fredrikson, M., \& Holm, L.-E. (1993). Psychosocial Factors Associated with Participation and Nonparticipation in a Diet Intervention Program. Journal of Psychosocial Oncology, ro(4), pp. 93-I07.

Nyblade, L.C., Menken, J., Wawer, M.J., Sewankambo, N.K., Serwadda, D., Makumbi, F., Gray, R.H. (20or). Populationbased HIV testing and counseling in rural Uganda: Participation and risk characteristics. Journal of acquired immune deficiency syndromes, 28(5), pp. 463-470.

Oakley, A., Strange, V., Stephenson, J., Forrest, S., \& Monteiro, H. (2004). Evaluating Processes: A Case Study of a Randomized Controlled Trial of Sex Education. Evaluation, Io, p. 22.

Olawaiye, D. (2010). The HIV risk of scholarised youth in Bugesera district, Rwanda: A scripting approach. (Master in Medicine), Ghent University, Gent, Belgium.

Painter, T.M., Diaby, K.L., Matia, D.M., Lin, L.S., Sibailly, T.S., Kouassims, M.K., Wiktor, S.Z. (2005). Sociodemographic factors associated with participation by HIV-1-positive pregnant women in an intervention to prevent mother-to-child transmission of HIV in Cote d'Ivoire. International Journal of Std \& Aids, I6(3), pp. 237-242.

Paul-Ebhohimhen, V., Poobalan, A., \& van Teijlingen, E.R. (2008). A systematic review of school-based sexual health interventions to prevent STI/HIV in sub-Saharan Africa. BMC public health, 8(4).

Plautz, A., Meekers, D., \& Neukom, J. (2003). The Impact of the Madagascar TOP R,seau Social Marketing Program on Sexual Behavior and Use of Reproductive Health Services (Vol. ): PSI Research Division: Working Paper No. 57. (Reprinted from: NOT IN FILE).

Robroek, S.J.W., van Lenthe, F.J., van Empelen, P., \& Burdorf, A. (2009). Determinants of participation in worksite health promotion programmes: a systematic review. International Journal of Behavioral Nutrition and Physical Activity, 6. doi: Artn 26 Doi io.II86/1479-5868-6-26.

Rotter, J.B. (I954). Social Learning and clinical psychology. New York: Prentice-Hall.

Speizer, I.S., Magnani, R.J., \& Colvin, C.E. (2003). The effectiveness of adolescent reproductive health interventions in developing countries: a review of the evidence. J Adolesc Health, 33 (5), pp. 324-348.

Speizer, I.S., Tambashe, B.O., \& Tegang, S.P. (200I). An Evaluation of the "Entre Nous Jeunes" Peer-educator Program for Adolescents in Cameroon. Studies in family planning, 3I(4), pp. 339-35I.

UNAIDS. (2012a). Country Situation Analysis Rwanda. Retrieved 6/4/2012, 2012, from http://www.unaids.org/en/regionscountries/countries/rwanda, accessed 6/4/2012. (2012b). Report on the Global AIDS Epidemic 2012². In UNAIDS (Ed.). Geneva: UNAIDS.

Underwood, C., Hachonda, H., Serlemitsos, E., \& Bharath-Kumar, U. (2006). Reducing the risk of HIV transmission among adolescents in Zambia: Psychosocial and behavioral correlates of viewing a risk-reduction media campaign. J Adolesc Health, 38(55), 55-е 5 I- 55 -еi3.

Underwood, C., Skinner, J., Osman, N., \& Schwandt, H. (20II). Structural determinants of adolescent girls' vulnerability to HIV: Views from community members in Botswana, Malawi, and Mozambique. Social science \& medicine, 73(2), pp. 343-350. doi: Io.ror6/j.socscimed.20Ir.05.044. 
UNFPA. (20II). Young People: The Greatest Hope for Turning the Tide.

UNFPA, \& FHI. (2005). Youth Peer Education Tooolkit: Standards for peer education programmes. New York.

Vanderstraten, A., King, R., Grinstead, O., Serufilira, A., \& Allen, S. (I995). Couple Communication, Sexual Coercion and Hiv Risk Reduction in Kigali, Rwanda. AIDS, 9(8), 935-944. doi: Doi I0.1097/00002030-199508000-00or6.

Wallston, K.A. (2005). The validity of the Multidimensional Health Locus of Control scales. Journal of Health Psychology, Io(5), 623-63I. doi: Doi Io.1177/1359105305055304.

WHO Regional Office for Europe and BZgA. (2010). Standards for Sexuality Education in Europe. A framework for policy makers, educational and health authorities and specialists. Cologne: Federal Centre for Health Education, BZgA.

Winter, L. (I988). The Role of Sexual Self-Concept in the Use of Contraceptives. Family Planning Perspectives, 20(3), pp. I23-I27.

Yang, H., Li, X., Stanton, B., Fang, X., Lin, D., Mao, R., Liu, H. (2007). Willingness to participate in HIV/STD prevention activities among Chinese rural-to-urban migrants. AIDS Education and Prevention, I6(6), pp. 557-570. 